\title{
Implementasi Algoritma Fuzzy Tsukamoto Pada Prototype Regulator Suhu Kandang Kelinci
}

\author{
Claude Calvin Alsher ${ }^{1}$, Halim Agung ${ }^{2}$ \\ ${ }^{1,2}$ Universitas Bunda Mulia; Jl. Lodan Raya No.2, 021-6909090 \\ ${ }^{3}$ Jurusan Teknik Informatika, Fakultas Teknik Dan Desain, Jakarta \\ e-mail: *11ccaletter@gmail.com, ${ }^{2}$ hagung@bundamulia.ac.id
}

\begin{abstract}
Abstrak
Banyak orang tertarik dalam memelihara kelinci karena dapat dijadikan sarana hiburan dengan melihat tingkah laku dari hewan yang dapat membuat pemiliknya terhibur karena hewan tersebut, tetapi banyak masyarakat yang kurang memahami cara memelihara kelinci dengan baik dan benar sehingga menyebabkan kelinci tersebut sakit dan bahkan sampai meninggal. Untuk mengatasi masalah tersebut maka di lakukan penelitian yang merancang suatu prototype yang menerapkan algoritma fuzzy tsukamoto pada prototype kandang kelinci dengan mengukur suhu yang ada pada kandang kelinci tersebut yang juga di pengaruhi oleh lingkungan sekitar kandang kelincinya dengan menggunakan sensor DHT11. Berdasarkan hasil penelitian dengan pengujian sebanyak $50 \mathrm{kali}$, sensor DHT11 dapat membaca suhu pada kandang kelinci sebesar $60 \%$ tingkat dan eror sebesar $40 \%$, dikarenakan perubahan cuaca dan suhu yang tidak dapat di prediksi.
\end{abstract}

Kata kunci: Kelinci, Fuzzy Tsukamoto, DHT11

\begin{abstract}
Many people are interested in caring for rabbits because they can be used as entertainment facilities by seeing the behavior of animals that can make their owners entertained because of the animals, but many people do not understand how to care for rabbits properly so that they cause illness and even death. To overcome this problem, a research was conducted to design a prototype that applies the Tsukamoto fuzzy algorithm to the rabbit cage prototype by measuring the temperature in the rabbit cage which is also influenced by the environment around the rabbit cage by using DH11 sensor. Based on the results of the study by testing 50 times, the DHT11 sensor can read the temperature in the rabbit cage by $60 \%$ level and error by $40 \%$, due to weather and temperature changes that cannot be predicted.
\end{abstract}

Keywords: Rabbit, Tsukamoto fuzzy, DHT11

\section{PENDAHULUAN}

K elinci merupakan golongan ternak herbivora yang mempunyai sifat coprophage/cecotrophy Sifat ini merupakan ciri khas dari kelinci, yaitu tingkah laku kelinci memakan kembali kotoran (faeces) lunak langsung dari anusnya (coprophage pellets) yang terjadi pada malam hari, sehingga disebut juga Ruminansia semu (pseudo-ruminant).Walaupun memiliki caecum (bagian pertama usus besar) yang besar, kemampuan kelinci dalam mencerna serat kasar terbatas, tidak sebanyak ruminansia. 
Dalam memelihara kelinci, kelangsungan hidupnya akan sangat tergantung perhatian dan tata laksana pemeliharaannya. Jenis, jumlah, dan mutu pakan yang diberikan sangat menentukan pertumbuhan, perkembangan, kesehatan, dan produksi [9].

Fungsi keanggotaan (membership function) adalah suatu kurva yang menunjukkan pemetaan titik-titik input data ke dalam nilai keanggotaannya (derajat keanggotaan) yang memiliki interval antara 0 sampai 1 [3]. Dalam Algoritma Fuzzy Tsukamoto ada tiga proses utama yaitu fuzzifikasi. Inferensi rules, dan defuzzifikasi. Fuzzifikasi dilakukan untuk mengubah input sistem yang mempunyai nilai tegas menjadi variabel linguistic. Saat proses evaluasi aturan dalam mesin inferensi, metode FuzzyTsukamoto menggunakan fungsi implikasi MIN untuk mendapatkan nilai $\alpha$-predikat tiap-tiap rule $(\alpha 1, \alpha 2, \alpha 3, \ldots \ldots$ an). Masing-masing nilai $\alpha$ predikat digunakan untuk menghitung hasil inferensi secara tegas (crisp) masing-masing rule (z1, z2, z3,... zn). defuzzyfikasi pada metode Tsukamoto menggunakan metode rata-rata (Average) [2]. Untuk membangun prototype kandang kelinci, peneliti menggunakan proses yaitu fuzzifikasi. Inferensi rules, dan defuzzifikasi dengan algoritma fuzzy tsukamotodengan metode prototypehasil dari ketiga proses tersebut di letakkan pada sensor suhu dan kelembaban (DHT11).

Pada penelitian sebelumnya yang dilakukan oleh Eko Didik Widianto, Mahfudhotul Khasanah, Agung Budi Prasetijo, dan Risma Septiana tahun 2017, dibangun sistem otomasi pada kandang kelinci sistem otomatisasi pembersihan kotoran dan pengaturan suhu kandang kelinci menggunakan papan Arduino Mega 2560 dan diimplementasikan dalam bentuk purwarupa. Sistem yang di bangun berbasis Arduino Mega dan menggunakan sensor DHT11 untuk mengukur suhu kandang kelinci dan sensor loadcell untuk otomatisasi pembersihan kandang kelincinya [1].

Penelitian sebelumnya dilakukan oleh L.P, Ayuningtias, Mohamad Irfan, dan Jumadi tahun 2017, dibangun sistem untuk memprediksi jumlah pendaftar untuk tahun ke depan, dilihat dari jumlah mahasiswa yang lulus dan registrasi dari tahun sebelumnya dan membandingkan perhitungannya menggunakan nilai rata-rata dari hasil yang diperoleh pada ketiga metode fuzzy tersebut dengan aplikasi berbasis web. Hasil dari penelitian yang telah dihitung, diperoleh bahwa metode fuzzy Mamdani mempunyai tingkat error yang lebih kecil sebesar $19,76 \%$ dibandingkan dengan metode Tsukamoto sebesar 39,03\% dan Sugeno sebesar $86,41 \%$ pada prediksi jumlah pendaftar mahasiswa baru [2].

Penelitian sebelumnya yang dilakukan oleh Muhammad Y.E.A., dan Hari Wibayant tahun 2013, dibangun sistem pengamatan suhu dan kelembaban pada rumah berbasis mikrokontroler ATmega8. Pada rancang bangun sistem minimum yang terkoordinasi oleh sensor DHT 11, alat dapat melakukan instruksi sesuai prosedur yang diharapkan dengan benar. Program dibuat dalam alur sistematis dengan sebuah pernyataan-pernyataan menggunakan software AVR STUDIO 5 yang nantinya progam diunggah ke dalam Chip mikrokontroller melalui port USB dengan menggunakan Programmer USB ISP. Pemrograman yang terdapat dalam chip mikrokontroller dibuat menggunakan bahasa pemrograman bahasa C. Untuk menjalankan sebuah instruksi dan sistem kerja yang dikendalikan oleh mikrokontroller ATmega8 ini, maka digunakan program yang dapat berjalan setelah berhasil pengecekandan mengunggahnya kedalam mikrokontroller dengan benar [4].

\section{METODE PENELITIAN}

\subsection{Fuzzy Tsukamoto}

Algoritma Logika Fuzzy Tsukamoto merupakan salah satu pembentuk soft computing. Logika Fuzzy Tsukamoto pertama kali diperkenalkan oleh Prof. Lotfi A. Zadeh pada tahun 1965. Dasar logika Fuzzy Tsukamoto adalah teori himpunan Fuzzy Tsukamoto. Pada teori 
himpunan Fuzzy Tsukamoto, peranan derajat keanggotaan sebagai penentu keberadaan elemen dalam suatu himpunan sangatlah penting. Nilai keanggotaan atau derajat keanggotaan atau membership function menjadi ciri utama dari penalaran dengan logika Fuzzy Tsukamoto tersebut. Logika Fuzzy Tsukamoto memiliki derajat keanggotaan dalam rentang 0 hingga 1. Berbeda dengan logika digital yang hanya memiliki dua nilai 1 atau 0. Logika Fuzzy Tsukamoto digunakan untuk menerjemahkan suatu besaran yang diekspresikan menggunakan bahasa (linguistic), misalkan besaran kecepatan laju kendaraan yang diekspresikan dengan pelan, agak cepat, cepat, dan sangat cepat. Dan logika Fuzzy Tsukamoto menunjukan sejauhmana suatu nilai itu benar dan sejauhmana suatu nilai itu salah. Logika Fuzzy Tsukamoto adalah suatu cara yang tepat untuk memetakan suatu ruang input kedalam suatu ruang output. Fuzzy Tsukamoto dinyatakan dalam derajat dari suatu keanggotaan dan derajat dari kebenaran. Oleh sebab itu sesuatu dapat dikatakan sebagian benar dan sebagian salah pada waktu yang sama [2].

Tahapan dalam Fuzzy Tsukamoto Tsukamoto [2]:

1. Fuzzifikasi

Fuzzifikasi dilakukan untuk mengubah input sistem yang mempunyai nilai tegas menjadi variabel linguistic.

2. Saat proses evaluasi aturan dalam mesin inferensi, metode Fuzzy Tsukamoto menggunakan fungsi implikasi MIN untuk mendapatkan nilai $\alpha$-predikat tiap-tiap rule $(\alpha 1, \alpha 2, \alpha 3, \ldots . \alpha \mathrm{n})$. Masing-masing nilai $\alpha$ predikat digunakan untuk menghitung hasil inferensi secara tegas (crisp) masing-masing rule (z1, z2, z3,... zn).

3. Proses defuzzyfikasi pada metode Tsukamoto menggunakan metode rata-rata (Average) dengan direpresentasikan pada rumusdefuzzifikasi (1). berikut:

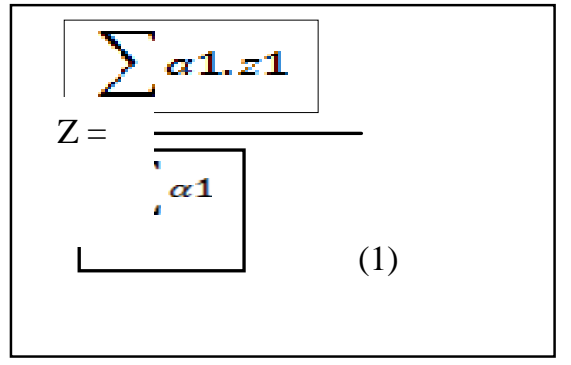

\subsection{Fungsi Keanggotaan}

Menurut Santoso, H [3]. Fungsi keanggotaan (membership function) adalah suatu kurva yang menunjukkan pemetaan titik-titik input data ke dalam nilai keanggotaannya (derajat keanggotaan) yang memiliki interval antara 0 sampai 1 . Untuk mendapatkan nilai keanggotaan dalam penelitian ini dengan melakukan fungsi sebagai berikut:

1. Representasi Linier

Pada representasi linier, pemetaan input ke derajat keanggotaannya digambarkan sebagai 2 garis lurus. Bentuk ini paling sederhana dan menjadi pilihan yang baik untuk mendekati suatu konsep yang kurang jelas. Dalam fungsi ini ada 2 keadaan himpunan fuzzy yang linier yaitu yang pertama adalah kenaikan himpunan dimulai pada nilai domain yang memiliki derajat keanggotaan nol (0) bergerak ke kanan menuju ke nilai domain yang memiliki derajat keanggotaan yang lebih tinggi. Hal ini direpresentasikan pada gambar 1 . 




Gambar 1. Representasi Linier Naik

Untuk representasi linier naik fungsi keanggotaanya digambarkan dalam ekspresi Rumus keanggotaan linier naik (2). berikut ini :

$$
\mu[x]=\left\{\begin{array}{lr}
1 ; & x \leq a \\
\frac{(x-a)}{(b-a)} ; & a \leq x \leq b \\
0 ; & x \geq b
\end{array}\right)
$$

Keadaan himpunan yang kedua merupakan kebalikan dari yang pertama, yaitu garis lurus dimulai dari nilai domain dengan derajat keanggotaan tertinggi pada sisi kiri, kemudian bergerak menurun kenilai domain yang memiliki nilai derajat keanggotaan yang lebih rendah seperti pada gambar 3 .

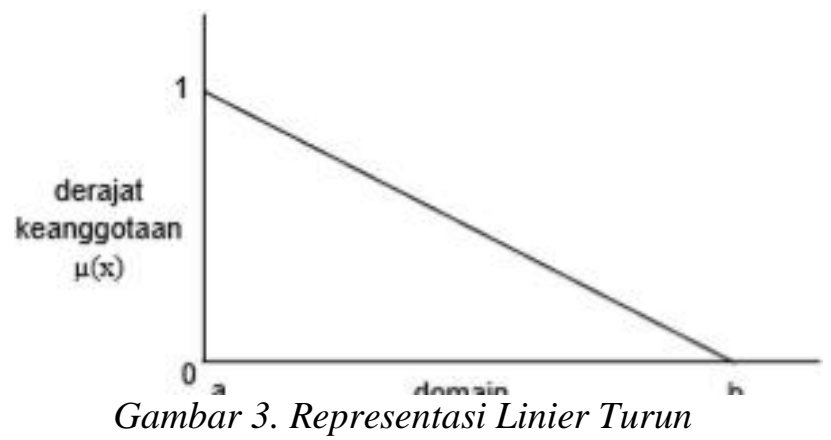

Untuk representasi linier turun fungsi keanggotaanya digambarkan dalam ekspresi berikut ini pada rumus fungi keanggotaan linier turun (3):

$$
\mu[x]=\left\{\begin{array}{lr}
\frac{(b-x)}{(b-a)} ; & a \leq x \leq b \\
0 ; & x \geq b
\end{array}\right.
$$

1)

2. Representasi Kurva Segitiga

Kurva segitiga pada dasarnya adalah merupakan gabungan antara 2 garis (linier) yang digambarkan pada Gambar 4.

Alsher et.al (Implementasi Algoritma Fuzzy Tsukamoto Pada Prototype Regulator Suhu Kandang Kelinci) 


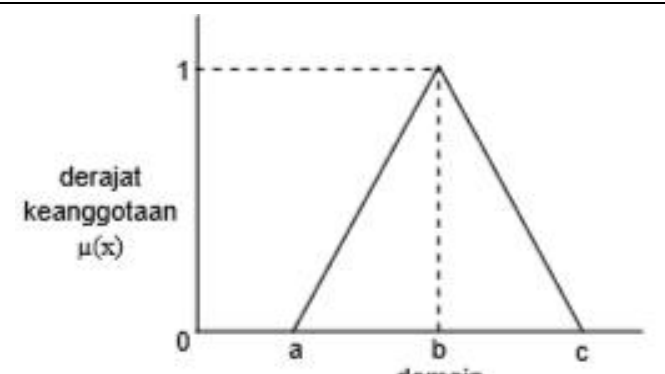

Gambar 4. Representasi Kurva Segitiga

Untuk representasi kurva segitiga fungsi keanggotaanya digambarkan dalam ekspresi berikut seperti pada Rumus (4) [3].

$$
\mu[x]=\left\{\begin{array}{lr}
0 ; & x \leq a \text { atau } x \geq c \\
\frac{(x-a)}{(b-a)} ; & a \leq x \leq b \\
\frac{(b-x)}{(c-b)} ; & \left.b \leq x \leq c_{4}\right)
\end{array}\right.
$$

\subsection{Sensor DHT11}

Menurut Muhammad Y.E.A., dan Hari Wibayanto [4] sensor DHT11 merupakan sensor dengan kalibrasi sinyal digital yang mampu memberikan informasi suhu dan kelembaban. DHT11 memiliki fitur kalibrasi yang sangat akurat. Koefisien kalibrasi ini disimpan dalam OTP program memory, sehingga ketika internal sensor mendeteksi sesuatu suhu atau kelembaban, maka module ini membaca koefisien sensor tersebut. Ukurannya yang kecil, dengan transmisi sinyal hingga 20 meter, membuat produk ini cocok digunakan untuk banyak pengukuran suhu dan kelembaban [4].

\subsection{Arduino}

Arduino [5] adalah pengendali mikro single-board yang bersifat open-source, diturunkan dari Wiring platform, dirancang untuk memudahkan penggunaan elektronik dalam berbagai bidang. Hardware yang memiliki prosesor Atmel $\underline{A V R}$ dan software memiliki bahasa pemrograman sendiri.

Arduino juga merupakan platform hardware terbuka yang ditujukan kepada siapa saja yang ingin membuat purwarupa peralatan elektronik interaktif berdasarkan hardware dan software yang fleksibel dan mudah digunakan. Mikrokontroler diprogram menggunakan bahasa pemrograman arduino yang memiliki kemiripan syntax dengan bahasa pemrograman C. Karena sifatnya yang terbuka maka siapa saja dapat mengunduh skema hardwarearduino dan membangunnya [5].

\subsection{Kelinci Angora}

Menurut Edi Busono, dan Dini Mardiani [6,7]. Kelinci Angora adalah salah satu jenis kelinci peliharaan tertua berasal dari Ankara Turki, pertama kali ditemukan dan dibawa ke Eropa oleh pelaut Inggris. Kemudian di bawa ke Perancis tahun 1723. Tahun 1777 Angora menyebar ke Jerman. Tahun 1920 pemeliharaan kelinci Angora meluas ke negara-negara Eropa Timur, Jepang, Kanada, dan Amerika Serikat. Sampai kini Prancis menjadi pusat peternakan kelinci angora terbesar yang ditujukan untuk menghasilkan wool. Di Indonesia kelinci jenis angora banyak diminati sebagai kelinci hias. Ada banyak jenis kelinci angora, misalnya French angora, German angora, Giant angora, English angora, Satin angora, Chinese angora, Swiss angora, Finnish angora, dsb.Warna bulunya bervariasi mulai putih, coklat, hitam, agouti, bintik-bintik putih, abu-abu, oranye, dan campuran atau kombinasi dari warna-warna tsb. 
Kelinci anggora memiliki ciri bulu yang tebal dan lembut di seluruh bagian permukaan tubuhnya [6]. Suhu Ekstrem. Suhu udara $18 \square$ batasan minimum suhu dingin yang dapat ditoleransi kelinci.Kisaran suhu yang ideal untuk kelinci Angora adalah 26-36 $\square$. Ketika suhu udara melebihi $43 \square$, harus disediakan pendinginan AC ruangan atau cara lainnya. Selama suhu ekstrim perawatan ekstra harus dilakukan terutama untuk anak kelinci dan kelinci baru dicukur [7].

\subsection{Model Perancangan Sistem}

Menurut Pressman, Roger S., dan Maxim, Bruce R [8]. Model perancangan sistem yang digunakan dalam membangun dan merancang sistem ini adalah model prototype. Tahapan model prototype dalam perancangan sistem ini dapat dilihat pada gambar 5 .

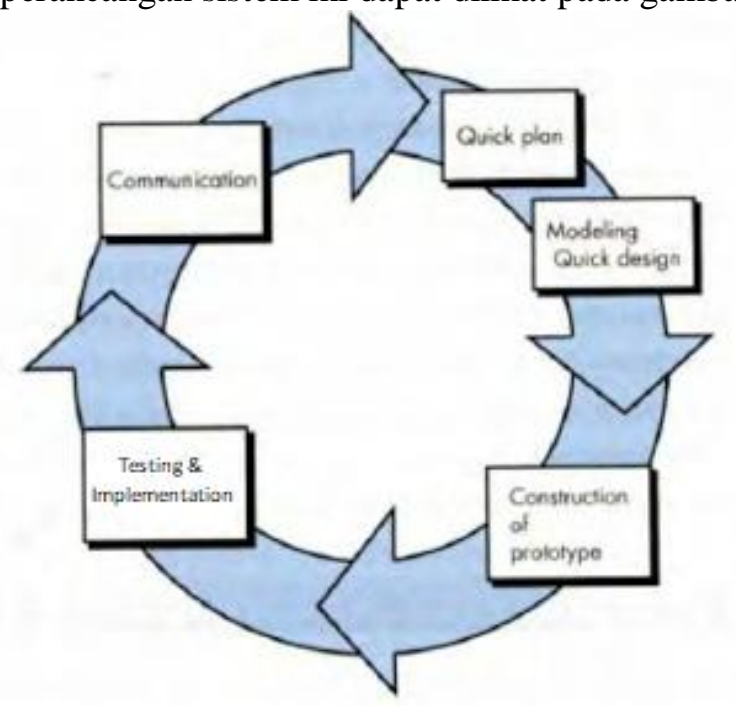

Gambar 5. Model Prototype

1. Communication

Pada tahap ini dilakukan komunikasi untuk menganalisa kebutuhan apa saja yang digunakan untuk merancang sistem prototype kandang kelinci.

2. Modelling Quick Design

Pada tahap ini dilakukan perancangan model atau rangka (desain rumah dan susunan alat) dari sistem prototype kandang kelinci.

3. Construction of Prototype

Pada tahap ini dilakukan perancangan prototype kandang kelinci berupa rancangan rumah, alat sensor beserta dengan implementasi koding.

4. Testing and Implementation

Pada tahap ini dilakukan pengujian prototype apakah telah sesuai dengan rancangan yang telah dibangun, serta adanya pengembangan prototype apabila terdapat kekurangan pada sistem yang telah dirancang [7].

\subsection{Relay}

Menurut Turang, Daniel Alexander Octavianus[9]. Relay biasanya digunakan untuk menggerakkan arus / tegangan yang besar (misalnya peralatan listrik 4 A / AC $220 \mathrm{~V}$ ) dengan memakai arus / tegangan yang kecil (misalnya 0.1 A / 12 Volt DC) [9]. 


\section{HASIL DAN PEMBAHASAN}

\subsection{Proses Penerapan Algoritma Fuzzy Tsukamoto}

Langkah AlgoritmaFuzzy Tsukamoto yang diterapkan pada sistem ini:

1. Fuzzifikasi

Data yang telah dimasukkan kemudian diubah menjadi variabel linguistic menggunakan fungsi keanggotaan pada suhu( dingin, normal, panas) sedangkan pada kelembaban (kering, normal, lembab). Pada sourcecode akan terlihat proses Fuzzyfikasi menggunakan rumus weighted average. Berikut merupakan batasan nilai untuk setiap variabel yang telah ditetapkan:

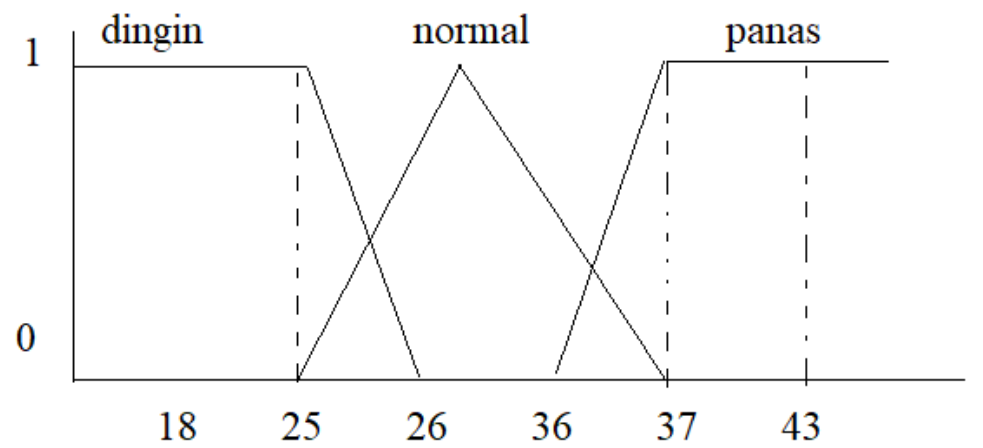

Gambar 6. Keanggotaan Himpunan Suhu

Pada gambar 6. Suhu mempunyai tiga variabel linguistic yaitu dingin, normal dan panas. Dingin memiliki batas nilai $18-25{ }^{\circ} \mathrm{C}$, normal dengan batas nilai $26-36{ }^{\circ} \mathrm{C}$ sedangkan panas memiliki batas nilai $37-43^{\circ} \mathrm{C}$.

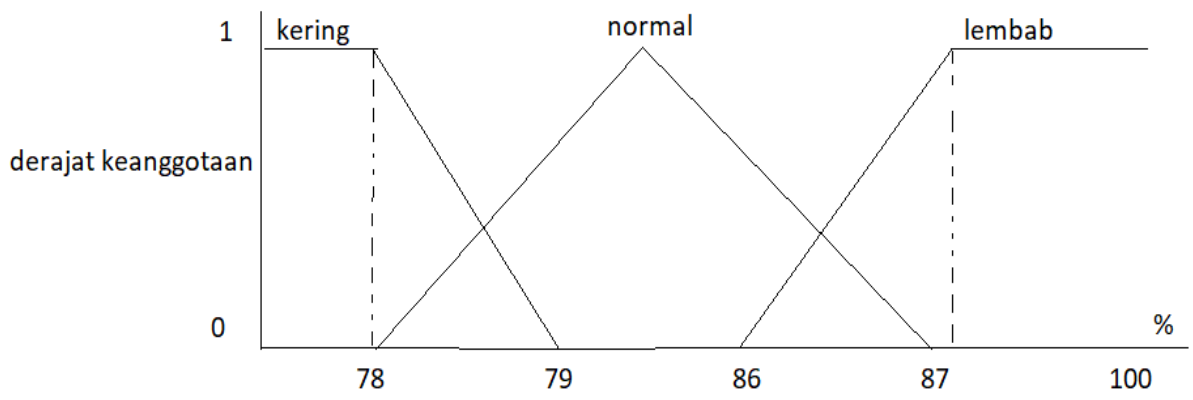

Gambar 7. Keanggotaan Himpunan Kelembaban

Gambar 7. Kelembaban mempunyai dua variabel linguistic yaitu kering memiliki batas nilai 0-78, lembab memliki batas nilai 87-100. sedangkan normal memiliki batas nilai 79-86 dalam satuan (\%).Batasan-batasan nilai tersebut akan diubah menjadi nilai derajat berkisar 0-1 dengan menggunakan rumus (2) dan rumus (3) Berikut merupakan implementasi rumus kedalam setiap variabel:

1) Suhu

a) Dingin

Suhu $<18 \Rightarrow \mu$ dingin[y] $=1$

Suhu $>25 \Rightarrow \mu$ dingin[y] $=0$

Suhu $>=18 \&<=25=>\mu$ dingin $[y]=25-y / 8$

b) Normal

Suhu $<26 \Rightarrow \mu$ dingin[y] $=1$

Suhu $>36 \Rightarrow \mu$ dingin $[\mathrm{y}]=0$ 
Suhu $>=26 \&<=36=>\mu \operatorname{dingin}[\mathrm{y}]=26-\mathrm{y} / 10$

c) Panas

Suhu $<37 \Rightarrow \mu$ panas $[\mathrm{y}]=0$

Suhu $>43 \Rightarrow \mu$ panas $[\mathrm{y}]=1$

Suhu $>=37 \&<=43=>\mu$ panas $[y]=y-37 / 6$

2) Kelembaban

a) Kering

Kelembaban $<0 \Rightarrow \mu$ kering $[\mathrm{y}]=1$

Kelembaban $>78 \Rightarrow \mu$ kering $[\mathrm{y}]=0$

Kelembaban $>=0 \quad \&<=78 \Rightarrow \mu$ kering $[\mathrm{y}]=78-\mathrm{y} / 78$

b) Normal

Kelembaban $<79=>\mu$ normal $[\mathrm{y}]=1$

Kelembaban $>86=>\mu$ normal $[\mathrm{y}]=0$

Kelembaban $>=79 \&<=86=>\mu$ normal[y] $=86-\mathrm{y} / 7$

c) Lembab

Kelembaban $<87=>\mu$ lembab[y] $=0$

Kelembaban $>100=>\mu$ lembab[y] $=1$

Kelembaban $>=87 \&<=100=>\mu$ lembab $[y]=y-87 / 13$

\subsection{Flowchart Diagram Algoritma}

Tujuan dari penelitian ini adalah menerapkan algoritma fuzzy tsukamoto pada protoype kandang kelinci sehingga sensor DHT11 dapat mengukur suhu dan kelembaban yang ada pada kandang kelinci yang juga di pengaruhi oleh lingkungan sekitarnya. Seperti pada Gambar 8.



Gambar 8. Flowchart Diagram Prototype Kandang Kelinci 
Gambar 8. Flowchart algoritma fuzzy Tsukamotoprototype kandang kelinci dimulai dengan sensor yang membaca keadaan lingkungan sekitar (suhu, kelembaban, cahaya dan berat). Jika kondisi hidup serta memenuhi aturan atau rule maka lampu penghangat akan menyala apabila suhu dingin dan jika panas kipas akan menyala di ikuti dengan kelembaban, lampu penerang akan menyala apabila kondisi lingkungan sekitar menjadi gelap. Timbangan dan mini servo akan menyala ssat menimbang tempat kotoran kelinci. Kondisi di luar rule menyebabkan sensor-sensor tidak bekerja atau apabila tidak di aliri dengan listrik maka komponen tersebut tidak menyala.

\subsection{Implementasi Dan Proses Algoritma}

Flowchart algoritma fuzzy tsukamoto dimulai dengan sensor yang membaca suhu dan kelembaban diproses dengan fuzzifikasi untuk mengubah nilai satuan tersebut menjadi variabel linguistic:

1. Nilai suhu menjadi dingin, normal, dan panas.

2. Nilai kelembabaan menjadi dingin, normal, dan lembab.

Variabel diproses kembali menggunakan rules menjadi output fuzzy dengan cara mengikuti aturan-aturan yang telah ditetapkan. Kemudian dilakukan proses defuzzifikasi untuk mengubah output fuzzy menjadi nilai pasti menggunakan fungsi keanggotaan yang telah dilakukan saat proses fuzzifikasi.

Pengujian yang dilakukan pada penelitian kali ini adalah dimana prototype di uji dengan menggunakan metode black box testing. Pengujiannya ialah dengan menguji seberapa baik sensor DHT11 dapat membaca suhu sekitar pada kandang kelinci yang dimana juga di pengaruhi oleh lingkungan sekitarnya. Pengujian di lakukan sebanyak 50 kali dimana jika suhu dan kelembaban ideal bagi kandang kelinci dapat di lihat dari tampilan $l c d$ dan responnya dari relay.Jika lampu penghangat menyala maka suhunya berada di bawah kondisi dinign dan kipas pendingin yang menyala maka suhunya berada pada kondisi panas sedangkan saat kondisi suhu ideal maka lampu penghangat dan kipas pendingin tidak menyala. Berikut tabel pengujiannya pada tabel 1. di mana keterangan B artinya berhasil sedangkan TB artinya tidak berhasil dalam membaca suhu.

Tabel 1. Pengujian Prototype Kandang kelinci

\begin{tabular}{|c|c|c|c|c|}
\hline $\begin{array}{c}\text { No } \\
\text { Pengujian }\end{array}$ & $\begin{array}{c}\text { Kondisi } \\
\text { Suhu }\left({ }^{\circ} \mathrm{C}\right)\end{array}$ & $\begin{array}{c}\text { Kipas } \\
\text { Pendingin }\end{array}$ & $\begin{array}{c}\text { Lampu } \\
\text { Penghangat }\end{array}$ & Hasil \\
\hline 1 & 32 & Mati & Mati & B \\
\hline 2 & 25 & Mati & Nyala & B \\
\hline 3 & 23 & Mati & Mati & B \\
\hline 4 & 39 & Nyala & Mati & B \\
\hline 5 & 28 & Mati & Mati & B \\
\hline 6 & 31 & Mati & Mati & B \\
\hline 7 & 25 & Mati & Mati & TB \\
\hline 8 & 30 & Mati & Mati & B \\
\hline 9 & 30 & Mati & Mati & TB \\
\hline 10 & 23 & Mati & Nyala & B \\
\hline 11 & 24 & Mati & Nyala & B \\
\hline 12 & 25 & Mati & Nyala & B \\
\hline 13 & 25 & Mati & Mati & TB \\
\hline 14 & 31 & Mati & Mati & B \\
\hline 15 & 28 & Mati & Mati & B \\
\hline 16 & 31 & Mati & Mati & TB \\
\hline
\end{tabular}


Vol. 5, No. 1, September 2018, Hal. 1-11

\begin{tabular}{|c|c|c|c|c|}
\hline 17 & 31 & Mati & Mati & B \\
\hline 18 & 31 & Mati & Mati & B \\
\hline 19 & 30 & Mati & Mati & $\mathrm{TB}$ \\
\hline 20 & 24 & Mati & Nyala & B \\
\hline 21 & 24 & Mati & Nyala & $\mathrm{B}$ \\
\hline 22 & 24 & Mati & Mati & $\mathrm{TB}$ \\
\hline 23 & 24 & Mati & Nyala & B \\
\hline 24 & 24 & Mati & Nyala & B \\
\hline 25 & 24 & Mati & Nyala & B \\
\hline 26 & 25 & Mati & Mati & $\mathrm{TB}$ \\
\hline 27 & 25 & Mati & Mati & $\mathrm{TB}$ \\
\hline 28 & 25 & Mati & Nyala & B \\
\hline 29 & 28 & Mati & Mati & TB \\
\hline 30 & 29 & Mati & Mati & B \\
\hline 31 & 30 & Mati & Mati & B \\
\hline 32 & 26 & Mati & Mati & TB \\
\hline 33 & 25 & Mati & Nyala & B \\
\hline 34 & 24 & Mati & Nyala & B \\
\hline 35 & 24 & Mati & Mati & $\mathrm{TB}$ \\
\hline 36 & 25 & Mati & Nyala & B \\
\hline 37 & 26 & Mati & Mati & $\mathrm{TB}$ \\
\hline 38 & 25 & Mati & Mati & TB \\
\hline 39 & 25 & Mati & Nyala & B \\
\hline 40 & 23 & Mati & Nyala & $\mathrm{B}$ \\
\hline 41 & 26 & Mati & Mati & B \\
\hline 42 & 27 & Mati & Mati & TB \\
\hline 43 & 28 & Mati & Mati & $\mathrm{TB}$ \\
\hline 44 & 28 & Mati & Mati & B \\
\hline 45 & 29 & Mati & Mati & $\mathrm{TB}$ \\
\hline 46 & 30 & Mati & Mati & B \\
\hline 47 & 31 & Mati & Mati & B \\
\hline 48 & 29 & Mati & Mati & TB \\
\hline 49 & 25 & Mati & Mati & TB \\
\hline 50 & 26 & Mati & Mati & B \\
\hline
\end{tabular}

\section{KESIMPULAN}

Berdasarkan pengujian yang telah dilakukan sebanyak 50 kali, yang dapat dilihat pada berdasarkan Tabel 1. sensor DHT11 dapat membaca suhu pada kandang kelinci sebesar $60 \%$ tingkat dan error sebesar $40 \%$, dikarenakan perubahan cuaca dan suhu yang tidak dapat di prediksi dan juga dapat mempengaruhi hasil pengujian di mana perbedaan iklim pada setiap daerah dan wilayah yang berbeda-beda.

\section{SARAN}

Beberapa saran untuk pengembangan pada penelitian ini selanjutnya adalah 
(1) menambahkan sensor air untuk mencegah air masuk saat terjadi hujan dan membuat seperti atap untuk melindungi komponen perangkat agar tidak mudah terkena air yang dapat bergerak otomatis dengan di kombinasikan sensor air dan lengan robot sebagai penggerak atap otomatis tersebut.

(2) menambahkan sensor solar panel untuk membantu menjaga suhu kandang sehingga apabila terlalu panas berdasarkan rentang suhu yang di tentukan maka atap otomatis yang pengeraknya lengan robot dapat menutupi bagian atas dari kandang kelinci.

\section{UCAPAN TERIMA KASIH}

Penulis mengucapkan terima kasih kepada Universitas Bunda Mulia yang telah memberi dukungan financial terhadap penelitian ini.

\section{DAFTAR PUSTAKA}

[1] Eko Didik Widianto, Mahfudhotul, Agung Budi Prasetjo, dan Risma Septiana. 2017, Sistem Otomasi Pembersihan Kotoran Pengaturan Suhu Kandang Kelinci Berbasis Arduimo Mega2560, Jurnal Rekayasa Elektrika, No.3, vol 13, hal 133, Universitas Syiah Kuala, Banda Aceh.

[2] Ayuningtias, L.P., Irfan, Mohamad, dan Jumadi. 2017, Analisa Perbandingan Logic Fuzzy Metode Tsukamoto, Sugeno, dan Mamdani (Studi Kasus: Prediksi Jumlah Pendaftar Mahasiswa Baru Fakultas Sains \& Teknologi Universitas Islam Negeri Sunan Gunung Djati Bandung, Jurnal Teknik Informatika, No.1, Vol.10, April 2017.

[3] Santoso, H. 2015, Panduan Praktis Arduino untuk Pemula, Elang Sakti, Trenggalek.

[4] Muhammad Y.E.A., Hari Wibayanto. 2013, Sistem Pengamatan Suhu dan Kelembaban Pada Rumah Berbasis Mikrokontroller Atmega8, Jurnal Teknik Elektro, No. 1, Vol. 5, Januari - Juni 2013, Universitas Negeri Semarang.

[5] Arduino. 2018, Arduino, Dipetik 08 08, 2018, dari Arduino: https://www.arduino.cc/en/Guide/Introduction.

[6] Busono, Edi., Dini Mardiani. 2015, Mengenal dan Memelihara Berbagai Jenis Kelinci Ras yang Populer di Indonesia. Koperasi Nukita, Bandung.

[7] Busono, Edi., Dini Mardiani. 2015, Wool Kelinci Angora Sebagai Industri Potensial Baru Serat Tekstil di Indonesia, Koperasi Nukita, Bandung.

[8] Pressman, Roger S., Maxim, Bruce R. copyright (C) 1996, 2001, 2005, 2009, 2014. Software Engineering: A Practicioner's Approach.

[9] Turang, Daniel Alexander Octavianus. 2015, Pengembangan Sistem Relay Pengendalian dan Penghematan Pemakaian Lampu Berbasis Mobile, Seminar Nasional Informatika 2015 UPN “Veteran", 14 November 2015, Yogyakarta.

[10] Satriawan, Dimas Dhica, Kumalasari, Erna. 2017, Sistem Pakar Mendiagnosa Penyakit Pada Kelinci Berbasis Web, Jurnal SCRIPT, No. 2,Vol. 4, hal 148-149, ISSN 2338-6304 